\title{
Correction to: The replacement of irreducible polynomial and affine mapping for the construction of a strong S-box
}

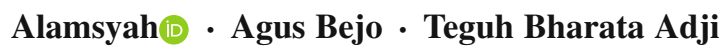

Published online: 3 August 2018

C) Springer Nature B.V. 2018

\section{Correction to: Nonlinear Dyn}

https://doi.org/10.1007/s11071-018-4310-2

In the original publication of the article, Tables 4 and 7 were incorrectly published. The corrected tables are shown below (Tables 4, 7).

The original article can be found online at https://doi.org/10. 1007/s11071-018-4310-2.

Alamsyah · A. Bejo · T. B. Adji $(\varangle)$

Department of Electrical Engineering and Information Technology, Universitas Gadjah Mada, Yogyakarta, Indonesia

e-mail: adji@ugm.ac.id
A. Bejo
e-mail: agusbj@ugm.ac.id

Alamsyah

Department of Computer Science, Universitas Negeri

Semarang, Kota Semarang, Indonesia

e-mail: alamsyah.16@mail.ugm.ac.id;

alamsyah@mail.unnes.ac.id 
Table 4 The proposed multiplicative inverse $m_{3}$

\begin{tabular}{|c|c|c|c|c|c|c|c|c|c|c|c|c|c|c|c|}
\hline 0 & 1 & 177 & 222 & 233 & 74 & 111 & 140 & 197 & 165 & 37 & 193 & 134 & 84 & 70 & 231 \\
\hline 211 & 93 & 227 & 133 & 163 & 52 & 209 & 237 & 67 & 166 & 42 & 99 & 35 & 158 & 194 & 119 \\
\hline 216 & 45 & 159 & 28 & 192 & 10 & 243 & 171 & 224 & 181 & 26 & 98 & 217 & 33 & 199 & 189 \\
\hline 144 & 86 & 83 & 234 & 21 & 162 & 128 & 121 & 160 & 91 & 79 & 229 & 97 & 73 & 138 & 205 \\
\hline 108 & 154 & 167 & 24 & 254 & 124 & 14 & 230 & 96 & 61 & 5 & 232 & 200 & 130 & 228 & 58 \\
\hline 112 & 106 & 235 & 50 & 13 & 135 & 49 & 145 & 221 & 246 & 161 & 57 & 210 & 17 & 239 & 191 \\
\hline 72 & 60 & 43 & 27 & 152 & 213 & 117 & 151 & 187 & 184 & 81 & 113 & 64 & 155 & 141 & 6 \\
\hline 80 & 107 & 156 & 142 & 150 & 102 & 195 & 31 & 129 & 55 & 149 & 178 & 69 & 255 & 215 & 136 \\
\hline 54 & 120 & 77 & 201 & 226 & 19 & 12 & 85 & 127 & 214 & 62 & 204 & 7 & 110 & 115 & 157 \\
\hline 48 & 87 & 175 & 248 & 179 & 122 & 116 & 103 & 100 & 212 & 65 & 109 & 114 & 143 & 29 & 34 \\
\hline 56 & 90 & 53 & 20 & 196 & 9 & 25 & 66 & 183 & 172 & 242 & 39 & 169 & 182 & 249 & 146 \\
\hline 223 & 2 & 123 & 148 & 225 & 41 & 173 & 168 & 105 & 186 & 185 & 104 & 198 & 47 & 238 & 95 \\
\hline 36 & 11 & 30 & 118 & 164 & 8 & 188 & 46 & 76 & 131 & 219 & 253 & 139 & 63 & 250 & 245 \\
\hline 236 & 22 & 92 & 16 & 153 & 101 & 137 & 126 & 32 & 44 & 252 & 202 & 247 & 88 & 3 & 176 \\
\hline 40 & 180 & 132 & 18 & 78 & 59 & 71 & 15 & 75 & 4 & 51 & 82 & 208 & 23 & 190 & 94 \\
\hline 241 & 240 & 170 & 38 & 251 & 207 & 89 & 220 & 147 & 174 & 206 & 244 & 218 & 203 & 68 & 125 \\
\hline
\end{tabular}

Table 7 The proposed S-box 3

\begin{tabular}{|c|c|c|c|c|c|c|c|c|c|c|c|c|c|c|c|}
\hline 99 & 224 & 105 & 111 & 173 & 152 & 101 & 176 & 207 & 95 & 158 & 193 & 171 & 181 & 138 & 184 \\
\hline 254 & 42 & 182 & 47 & 86 & 37 & 249 & 163 & 7 & 219 & 8 & 119 & 151 & 143 & 69 & 65 \\
\hline 102 & 130 & 12 & 73 & 66 & 120 & 142 & 74 & 50 & 103 & 64 & 244 & 229 & 144 & 200 & 123 \\
\hline 154 & 178 & 63 & 41 & 214 & 213 & 162 & 84 & 210 & 35 & 21 & 191 & 112 & 28 & 185 & 211 \\
\hline 225 & 129 & 88 & 71 & 31 & 217 & 118 & 59 & 243 & 186 & 238 & 46 & 94 & 165 & 60 & 48 \\
\hline 203 & 232 & 170 & 44 & 242 & 40 & 168 & 25 & 235 & 3 & 81 & 180 & 125 & 216 & 164 & 124 \\
\hline 159 & 57 & 139 & 195 & 134 & 247 & 70 & 16 & 114 & 246 & 56 & 72 & 131 & 2 & 51 & 106 \\
\hline 187 & 107 & 136 & 183 & 147 & 250 & 198 & 205 & 33 & 161 & 23 & 237 & 14 & 156 & 240 & 190 \\
\hline 34 & 215 & 18 & 221 & 53 & 223 & 113 & 54 & 93 & 115 & 62 & 80 & 233 & 230 & 79 & 11 \\
\hline 43 & 49 & 68 & 22 & 110 & 208 & 197 & 121 & 253 & 116 & 0 & 98 & 204 & 52 & 202 & 20 \\
\hline 55 & 160 & 166 & 85 & 76 & 252 & 196 & 132 & 96 & 192 & 13 & 153 & 77 & 227 & 149 & 157 \\
\hline 236 & 100 & 83 & 148 & 177 & 140 & 67 & 206 & 108 & 241 & 117 & 239 & 75 & 133 & 39 & 45 \\
\hline 29 & 251 & 78 & 194 & 220 & 127 & 248 & 6 & 145 & 38 & 226 & 155 & 58 & 189 & 17 & 135 \\
\hline 32 & 82 & 169 & 91 & 5 & 126 & 61 & 222 & 19 & 1 & 24 & 89 & 128 & 167 & 231 & 234 \\
\hline 15 & 228 & 172 & 92 & 150 & 179 & 9 & 245 & 27 & 109 & 175 & 188 & 122 & 209 & 255 & 174 \\
\hline 137 & 10 & 201 & 26 & 146 & 212 & 36 & 104 & 30 & 199 & 87 & 4 & 97 & 218 & 141 & 90 \\
\hline
\end{tabular}

